Check for updates

Cite this: RSC Adv., 2017, 7, 38335

\title{
Photoresponsive amphiphilic block macrocycles bearing azobenzene side chains $\dagger$
}

\author{
Lishan Li, Ye Cai, Zhengbiao Zhang, (D) Wei Zhang, (D) Nianchen Zhou* and Xiulin Zhu*
}

\begin{abstract}
Topological molecular architectures play a crucial role in the self-assembly of amphiphilic block copolymers. Many characteristics of macromolecules originate from the special properties of the ends of molecules. Herein, we synthesized well-defined cyclic block copolymers bearing hydrophobic azobenzene and hydrophilic carboxyl moieties in their side-chains, cyclic-PBHME $E_{m}-b-\mathrm{PAA}_{n}$, via sequential atom transfer radical polymerization (ATRP) and intramolecular $\mathrm{Cu}($ ()-catalyzed azide/alkyne cycloaddition (CUAAC) cyclization reaction followed by the selective hydrolysis of tert-butyl ester. The successful synthesis of the amphiphilic block copolymers was fully characterized via conventional gel permeation chromatography, triple detection gel permeation chromatography, nuclear magnetic resonance, Fourier transform infrared spectroscopy, and matrix-assisted laser desorption ionization time-of-flight mass spectrometry. Via investigating the properties of the cyclic polymer, we observed that the cyclic structure displayed faster photoisomerization in solution than its linear precursor. Moreover, the cyclic copolymer exhibits larger changes in the size and morphology of the selfassembled aggregates upon $365 \mathrm{~nm}$ light irradiation as compared to its linear counterpart. These interesting findings show that the topological cyclic architecture greatly affects the photoisomerization of azobenzene and copolymeric packing behavior in micellar aggregates.
\end{abstract}

Received 15th June 2017 Accepted 19th July 2017

DOI: $10.1039 / \mathrm{c} 7 \mathrm{ra06688 \textrm {k }}$

rsc.li/rsc-advances differences in the shape and dipole moment of trans- and cisazobenzene. ${ }^{13-17}$ In addition, azobenzene can undergo cleavage of the azo bond upon treatment with some reductives or azoreductase. Notably, polymeric azobenzene amphiphiles display versatile properties, such as micelle dissociation, colloid deformation, and vesicle bursting and fusion, and promising applications for various nanostructures in the self-assembly systems. ${ }^{18-28}$ Polymer-based azobenzene, as one of the most attractive responsive materials, has been subjected to extensive

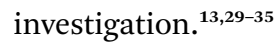

As one of the most important topological polymers, cyclic polymers represent an interesting class of materials since they usually exhibit unique and improved properties as compared to their linear analogues. ${ }^{36-45}$ Recent advances in macrocycles have demonstrated that the cyclic architecture displays profound effects on the photo-responsive properties, such as liquid crystal formation, birefringence, fluorescence emission, and photoinduced surface relief grating formation, of azobenzenecontaining polymers. ${ }^{46-48}$ Moreover, the self-assembly behavior and properties of amphiphilic copolymers are also found to be sensitive to the endless topology such as morphology, particle dimension, and stability of the self-assembled aggregates. ${ }^{49-56}$

Rational macromolecular design inspired us to construct cyclic polymeric azobenzene amphiphiles to gain new insights into their structure-property relationship. Herein, we designed and synthesized cyclic amphiphilic block copolymers bearing
State and Local Joint Engineering Laboratory for Novel Functional Polymeric Materials, Jiangsu Key Laboratory of Advanced Functional Polymer Design and Application, College of Chemistry, Chemical Engineering and Materials Science, Soochow University, Suzhou, 215123, P. R. China. E-mail: nczhou@suda.edu.cn; xlzhu@suda.edu.cn

$\dagger$ Electronic supplementary information (ESI) available: Materials, polymer characterization data, DLS and UV-vis data. See DOI: 10.1039/c7ra06688k 

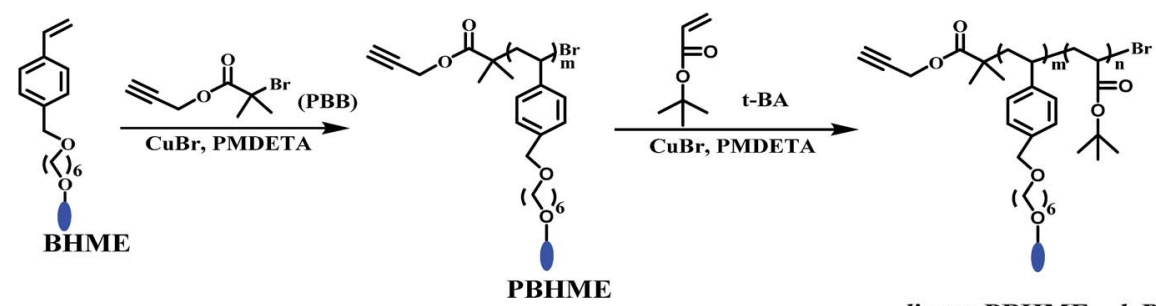

linear-PBHME $\mathrm{m}_{\mathrm{m}}-\mathrm{b}-\mathrm{Pt}-\mathrm{BA}_{\mathrm{n}}-\mathrm{Br}$

.

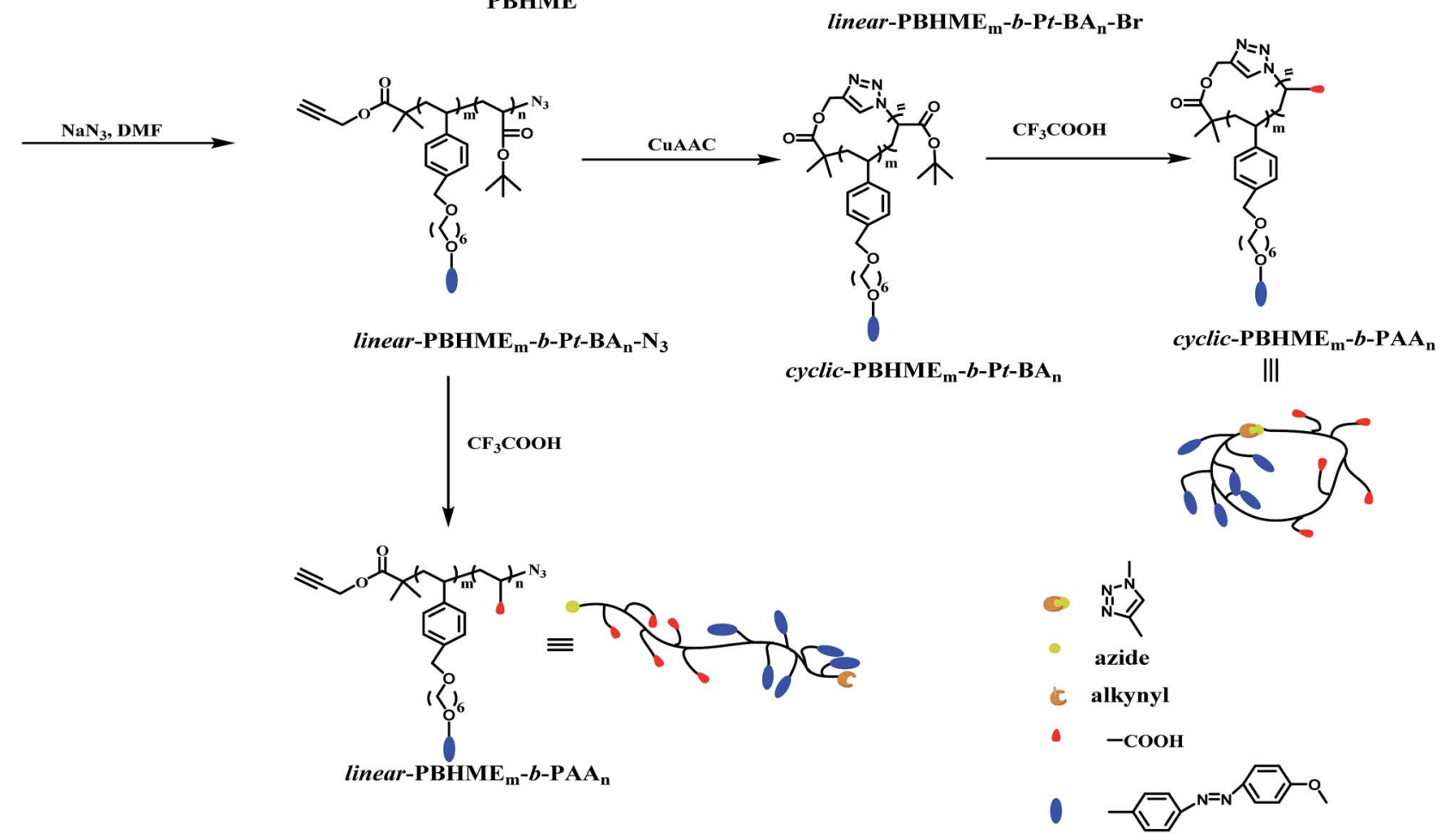

Scheme 1 Synthetic routes for linear-PBHME $m-b-\mathrm{PAA}_{n}$ and cyclic-PBHME $m-b-\mathrm{PAA}_{n}$.

pendent hydrophobic azobenzene and hydrophilic carboxyl groups, cyclic- $\mathrm{PBHME}_{m}-b-\mathrm{PAA}_{n}$, via successive atom transfer radical copolymerization (ATRP), $\mathrm{Cu}(\mathrm{I})$-catalyzed azide/alkyne cycloaddition (CuAAC) click chemistry, ${ }^{57}$ and selective hydrolysis of tert-butyl ester. The synthetic routes for cyclic-PBHME $m^{-}$ $b$ - $\mathrm{PAA}_{n}$ are shown in Scheme 1. Furthermore, we mainly investigated the self-assembly behavior and photoresponsive performance of the resultant cyclic amphiphile; it was observed that the cyclic topology endowed unique properties to cyclicPBHME $_{m}-b-\mathrm{PAA}_{n}$ as compared to that of its linear counterpart.

\section{Results and discussion}

Synthesis and characterization of linear-PBHME ${ }_{m}-b-\mathrm{Pt}_{-} \mathrm{BA}_{n}$ and cyclic-PBHME ${ }_{m}-b$-Pt-BA

The synthetic routes for linear- and cyclic-PBHME ${ }_{m}-b-\mathrm{PAA}_{n}$ are shown in scheme 1. The ATRP initiator propargyl-2bromoisobutyrate (PBB) with an terminal alkyne and styrene monomer bearing azobenzene [(6-(4-benzyloxy)hexyloxy)-(4methoxyphenyl-azo)]ethylene (BHME) were prepared according to previous study.$^{58}$ First, the homopolymer (PBHME) with $\alpha$ alkyne- $\omega$-bromine was synthesized via ATRP polymerization of the functionalized monomer BHME in anisole using the PBB initiator. The molecular weights of the PBHME were roughly evaluated from the feeding ratio of the reactants and polymerization conversion. PBHME $_{10}$ with 10 repeating BHME units $(\mathrm{m})$ was obtained, based on the ${ }^{1} \mathrm{H}$ NMR spectra of PBHME (Fig. S1 $\dagger$ ) and calculation according to Formula S1. $\dagger$ The block copolymers with $\alpha$-alkyne- $\omega$-bromine, linear-PBHME ${ }_{m}-b-\mathrm{P}^{-\mathrm{BA}_{n}-}$ $\mathrm{Br}$, were then prepared via ATRP chain-extension using PBHME $_{10}$ as the macro-ATRP initiator and $t$-BA as the second monomer. The number-average molecular weights $\left(M_{\mathrm{n}}\right)$ determined by gel permeation chromatography (GPC) increased to $5600 \mathrm{~g} \mathrm{~mol}^{-1}$ from the original value of $5100 \mathrm{~g} \mathrm{~mol}^{-1}$, and narrow molecular weight distributions $\left(M_{\mathrm{w}} / M_{\mathrm{n}}\right)$ were exhibited after chain-extension (Fig. S2 $\dagger$ ). The repeating $t$-BA units $(n)$ of the block copolymer were calculated based on the ${ }^{1} \mathrm{H}$ NMR spectra of the copolymer (Fig. S1 $\dagger$ ) and Formula S2, $\dagger$ which indicated the synthesis of the copolymer linear-PBHME $10-b-\mathrm{P} t$ $\mathrm{BA}_{3}-\mathrm{Br}$. The linear precursor linear-PBHME $\mathrm{B}_{10}-b-t-\mathrm{BA}_{3}-\mathrm{N}_{3}$ was prepared from linear- $\mathrm{PBHME}_{10}-b-t-\mathrm{BA}_{3}-\mathrm{Br}$ via nucleophilic substitution reaction with $\mathrm{NaN}_{3}$. Cyclic-PBHME 10 - $b-t-\mathrm{BA}_{3}$ was prepared via the copper(I)-catalyzed azide-alkyne cycloaddition (CuAAC) of linear-PBHME $10-b-\mathrm{P}-\mathrm{BA}_{3}-\mathrm{N}_{3}$ in highly diluted DMF solutions (the detailed process is provided in the ESI $\uparrow$ ). The successful preparation of the cyclic polymer was verified by gel 

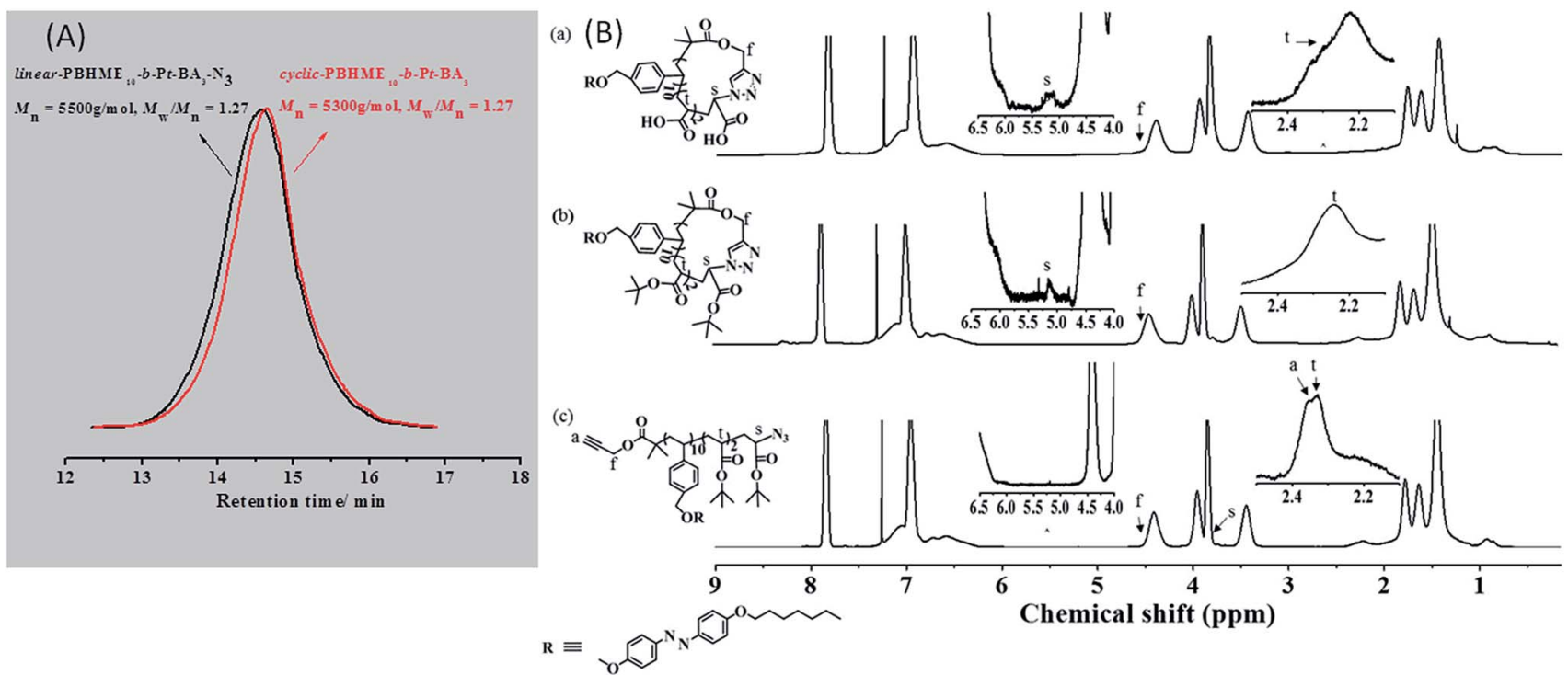

Fig. 1 (A) GPC traces of cyclic-PBHME $10-b-P t-B A_{3}$ and linear-PBHME $10-b-t-B_{3}-N_{3}$ using THF as the eluent. (B) ${ }^{1} \mathrm{H} N M R$ spectra of cyclic$\mathrm{PBHME}_{10}-b-t-\mathrm{AA}_{3}(\mathrm{a})$, cyclic-PBHME $10-b-t-\mathrm{BA}_{3}$ (b), and linear-PBHME $10-b-t-\mathrm{BA}_{3}-\mathrm{N}_{3}$ (c).

permeation chromatography (GPC), triple-detection GPC (TDGPC), Fourier transform infrared (FTIR) and proton nuclear magnetic resonance $\left({ }^{1} \mathrm{H}\right.$ NMR $)$ spectroscopy, and matrix assisted laser desorption/ionization time of flight (MALDI-TOF) mass spectrometry. The GPC curves of cyclic-PBHME $10-b$-Pt$\mathrm{BA}_{3}$ and its linear-precursor present a symmetric peak with a narrow molecular weight distribution (Fig. 1). The cyclicsample shifted to a longer elution time as compared to the linear precursor; this can be attributed to the fact that the more compact cyclic architecture reduces the hydrodynamic volume. The number-average molecular weight $\left(M_{\mathrm{n}, \mathrm{GPC}}\right.$ and $\left.M_{\mathrm{n}, \mathrm{NMR}}\right)$ of the linear- and cyclic-PBHME 10 - $b$ - $\mathrm{P} t-\mathrm{BA}_{3}$ obtained by GPC measurement and calculated based on the ${ }^{1} \mathrm{H}$ NMR spectra are shown in Table 1. By monitoring the FTIR spectra, it was observed that the characteristic signals of azide at $2100 \mathrm{~cm}^{-1}$ and alkyne at $3300 \mathrm{~cm}^{-1}$ for linear-PBHME ${ }_{10}-b-\mathrm{P}^{-}-\mathrm{BA}_{3}$ disappeared after CuAAC cyclization (Fig. S3(A) $\dagger$ ). The comparison of the ${ }^{1} \mathrm{H}$ NMR spectra of the linear- and cyclic-copolymers (Fig. 1(B)) shows that the signal at around 2.3-2.4 ppm (a), which corresponds to the terminal alkynyl proton of the linearsample, disappears in the cyclic-sample, and the characteristic signal at around $3.7 \mathrm{ppm}(\mathrm{s})$ adjacent to the azide group in the linear-sample shifts to 5.0-5.5 ppm after ring closure due to the formation of triazole. ${ }^{59}$ Moreover, cyclic-PBHME $\mathrm{P}_{10}-b-\mathrm{P}^{\mathrm{P}}-\mathrm{BA}_{3}$ was further confirmed by TD-GPC and MALDI-TOF mass spectrometry measurements. The number-average molecular weights $\left(M_{\mathrm{n}, \mathrm{TD}-\mathrm{GPC}}\right)$, absolute molecular weights $\left(M_{\mathrm{w}, \mathrm{TD}-\mathrm{GPC}}\right)$, intrinsic viscosity values $([\eta])$, and hydrodynamic radius $\left(R_{\mathrm{h}}\right)$ of the linear- and cyclic-copolymers analyzed by TD-GPC are shown in Table 1 (the TD-GPC traces are displayed in Fig. S4 $\dagger$ ). ${ }^{60,61}$ It is observed that the $M_{\mathrm{w}, \mathrm{TD}-\mathrm{GPC}}$ of cyclic$\mathrm{PBHME}_{10}-b-\mathrm{P} t-\mathrm{BA}_{3}$ is consistent with that of its linear precursor. Moreover, the cyclic polymer exhibits a smaller $[\eta]$ value as compared to its linear counterpart; this can be ascribed to the cyclic topology. The MALDI-TOF mass spectra of cyclic- and linear-PBHME ${ }_{10}-b-\mathrm{Pt}-\mathrm{BA}_{3}$ are shown in Fig. $\mathrm{S} 5, \dagger$ and the corresponding mass data are listed in Table S1.† All series of mass peaks of the linear- and cyclic-copolymers can be well assigned and are in good agreement with the theoretical peaks. These abovementioned results strongly support the successful preparation of well-defined cyclic-PBHME $10-b-\mathrm{Pt}^{-\mathrm{BA}_{3}}$.

Table 1 The number-average molecular weights $\left(M_{n}\right)$, molecular weight distribution $\left(M_{w} / M_{n}\right)$, absolute molecular weights $\left(M_{w, T D}\right.$-GPC), intrinsic viscosity $([\eta])$, and hydrodynamic radius $\left(R_{\mathrm{h}, \mathrm{TD}-\mathrm{GPC}}\right)$ of cyclic-PBHME $\mathrm{H}_{10}-b-t-\mathrm{BA}_{3}$ and linear-PBHME $10-b-t-\mathrm{BA}_{3}-\mathrm{N}_{3}$ determined by conventional GPC and three detection GPC (TD-GPC) as well as ${ }^{1} \mathrm{H}$ NMR spectra ${ }^{a}$

\begin{tabular}{|c|c|c|c|c|}
\hline GPC & \multicolumn{4}{|c|}{ TD-GPC } \\
\hline & & & & 0.1977 \\
\hline & & & & 0.1977 \\
\hline
\end{tabular}

${ }^{a} \mathrm{~L}$ : linear-PBHME ${ }_{10}-b-t-\mathrm{BA}_{3}-\mathrm{N}_{3}$, C: cyclic-PBHME $\mathrm{P}_{10}-b-t-\mathrm{BA}_{3} \cdot{ }^{b}$ The $\mathrm{d} n / \mathrm{d} c$ values for the linear polymer were determined by Wyatt Optilab rEX using at least three different concentrations. The $\mathrm{d} n / \mathrm{d} c$ value of the cyclic polymer was assumed to be equal to that of the linear precursor. ${ }^{60,61}$ 
Selective hydrolysis of linear- and cyclic-PBHME ${ }_{m}-b-P t-B_{n}$

The linear- and cyclic- $\mathrm{P}\left(\mathrm{BHME}_{10}-b-t-\mathrm{BA}_{3}\right)$ were then reacted with trifluoroacetic acid at room temperature to convert $t$-BA into acrylic acid (AA) via selective hydrolysis. ${ }^{59}$ The successful selective hydrolysis was confirmed by FT-IR, ${ }^{1} \mathrm{H}$ NMR, and ${ }^{13} \mathrm{C}$ NMR (Fig. 1(B) and $\mathrm{S} 3 \dagger$ ). The ${ }^{13} \mathrm{C}$ NMR and FT-IR spectra in Fig. $\mathrm{S} 3 \dagger$ showed that the tert-butyl ester groups entirely disappeared and transformed into carboxyl groups after the hydrolysis. Moreover, as compared to those of the ${ }^{1} \mathrm{H}$ NMR spectra of the cycliccopolymers obtained before and after hydrolysis, the two characteristic peaks at around $4.4 \mathrm{ppm}$ (f) of the methylene protons adjacent to the ester groups were exactly the same, indicating that the ester groups in the cyclic backbone were not damaged during the selective hydrolysis.

Glass transition temperature $\left(T_{\mathrm{g}}\right)$ and photoisomerization of the cyclic biblock amphiphilic copolymer in a THF solution

The glass transition temperature $T_{\mathrm{g}}$ of the linear- and cyclic$\mathrm{PBHME}_{10}-b-\mathrm{PAA}_{3}$ was evaluated via differential scanning calorimetry (DSC). As shown in Table 2, the $T_{\mathrm{g}}$ of the cyclic sample was higher than that of its linear counterpart; this can be attributed to the absence of main-chain ends in the macrocycle. ${ }^{42,62}$ Both the linear and cyclic copolymers showed only one $T_{\mathrm{g}}$ during the DSC measurement perhaps because the AA units in the block copolymers have a smaller ratio.

The photoisomerization of trans-to-cis and cis-to-trans of the linear- and cyclic-PBHME ${ }_{10}-b-\mathrm{PAA}_{3}$ in THF was investigated and compared under $365 \mathrm{~nm}$ and $435 \mathrm{~nm}$ light irradiation at different time intervals until the photo-stationary state was achieved (Fig. 2). The first-order kinetics curves of the photoisomerization are plotted in Fig. 3 on the basis of the Formulas $\mathrm{S} 3$ and $\mathrm{S} 4, \dagger$ and then, the rate constants $\left(k_{\mathrm{e}}\right.$ and $\left.k_{\mathrm{H}}\right)$ of the cyclicand linear-PBHME $10-b-\mathrm{PAA}_{3}$ and the cyclic/linear ratio were calculated and are summarized in Table 2. The cyclic product displays larger $k_{\mathrm{e}}$ and $k_{\mathrm{H}}$ values, indicating that the cyclic sample has faster photoisomerization than its linear precursor. We speculate that the more flexible linear polymer may have a higher degree of random coil conformations as compared to the cyclic polymer without main-chain ends, which probably leads a more transition resistance for its trans-to-cis isomerization. $^{14,48}$

Table 2 Glass transition temperatures $\left(T_{\mathrm{g}}\right)$ of linear- and cyclic$\mathrm{PBHME}_{10}-b-\mathrm{PAA}_{3}$ determined by differential scanning calorimetry (DSC) and kinetic parameters for the trans-to-cis and cis-to-trans isomerization of linear- and cyclic- $\mathrm{PBHME}_{10}-b-\mathrm{PAA}_{3}$ in THF solution ${ }^{e}$

\begin{tabular}{lllllll}
\hline Sample & $\begin{array}{l}T_{\mathrm{g}}, \\
{ }^{\circ} \mathrm{C}\end{array}$ & $\begin{array}{l}\Delta T_{\mathrm{g}}, \\
{ }^{\circ} \mathrm{C}\end{array}$ & $\begin{array}{l}k_{\mathrm{e}}{ }^{a} \times \\
10^{-3} \mathrm{~s}^{-1}\end{array}$ & $\begin{array}{l}k_{\mathrm{e}} / \\
k^{\prime}{ }_{\mathrm{e}}{ }^{b}\end{array}$ & $\begin{array}{l}k_{\mathrm{H}}{ }^{c} \times \\
10^{-4} \mathrm{~s}^{-1}\end{array}$ & $\begin{array}{l}k_{\mathrm{H}} / \\
k_{\mathrm{H}}^{\prime}{ }^{d}\end{array}$ \\
\hline $\mathrm{L}$ & 44 & 11 & 2.25 & 2.43 & 0.62 & 1.98 \\
$\mathrm{C}$ & 55 & & 5.46 & & 1.23 &
\end{tabular}

${ }^{a}$ Rate constant of trans-to-cis photoisomerization. ${ }^{b}$ Rate constant ratio of trans-to-cis isomerization of the cyclic-polymer relative to the linearpolymer. ${ }^{c}$ Rate constant of trans-to-cis recovery. ${ }^{d}$ Rate constant ratio of cis-to-trans recovery of the cyclic-polymer relative to the linearpolymer. ${ }^{e} \mathrm{~L}$ : linear-PBHME ${ }_{10}-b-\mathrm{PAA}_{3}-\mathrm{N}_{3}$ and C: cyclic-PBHME ${ }_{10}-b-\mathrm{PAA}_{3}$.

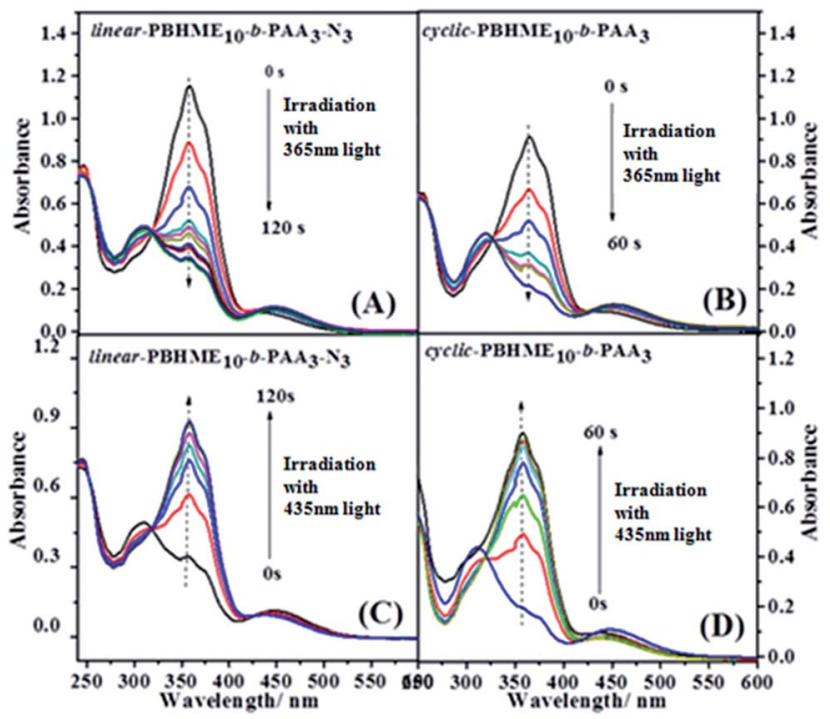

Fig. 2 UV-vis absorption changes of linear- and cyclic-PBHME ${ }_{10}-b-$ $\mathrm{PAA}_{3}$ in THF at different time intervals as a function of $365 \mathrm{~nm}(1 \mathrm{~mW}$ $\left.\mathrm{cm}^{-2}\right)(A$ and $B)$ and $435 \mathrm{~nm}\left(60 \mathrm{~mW} \mathrm{~cm}^{-2}\right)(C$ and $D)$ light irradiation at room temperature, respectively. The concentration of the solution is $2.0 \times 10^{-5} \mathrm{~g} \mathrm{~mL}^{-1}$.

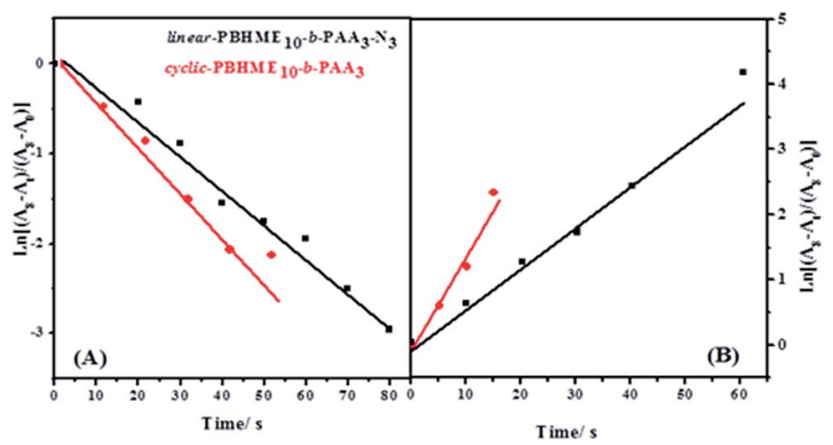

Fig. 3 First-order kinetic curves for the trans-to-cis photoisomerization of linear- and cyclic- $\mathrm{PBHME}_{10}-b-\mathrm{PAA}_{3}$ during irradiation with $365 \mathrm{~nm}$ UV light $\left(1 \mathrm{~mW} \mathrm{~cm}{ }^{-2}\right)$ (A) and first-order kinetics curves for cis-to-trans recovery during irradiation with $435 \mathrm{~nm}$ light $(60 \mathrm{~mW}$ $\mathrm{cm}^{-2}$ ) (B). The concentration of the polymers in THF is $2.0 \times 10^{-5} \mathrm{~g}$ $\mathrm{mL}^{-1}$.

Self-assembly behaviors and photo-responsive performance of the aggregates from linear- and cyclic-PBHME ${ }_{m}-b-\mathbf{P A A}_{n}$

The self-assembly behavior of cyclic-PBHME $E_{10}-b-\mathrm{PAA}_{3}$ was investigated using a mixture solution of water/THF. The selfassembly of the linear precursor was conducted under the same conditions as its cyclic counterpart to identify the influence of the cyclic structure on its properties. A representative self-assembly solution was directly prepared by slowly adding water to a solution of the polymer in THF with an initial concentration of $0.20 \mathrm{mg} \mathrm{mL} \mathrm{mL}^{-1}$ until the mixture solution reached the ratio of $3 / 10(\mathrm{v} / \mathrm{v})$ of water/THF. The morphology and sizes of the self-assembled micellar aggregates were verified via transmission electron microscopy (TEM) and dynamic light scattering (DLS). Both the cyclic and linear amphiphilic 


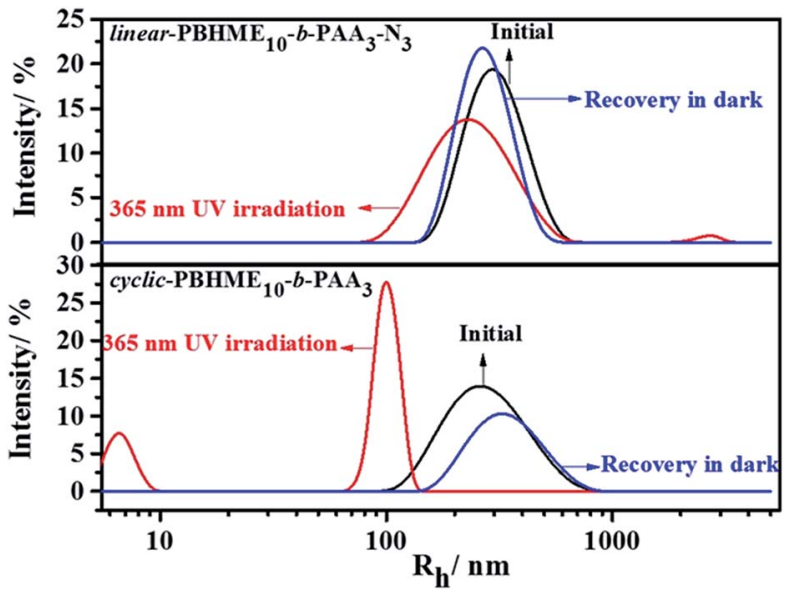

Fig. 4 Hydrodynamic radius $\left(R_{\mathrm{h}}\right)$ distribution of the aggregates formed by linear- $\mathrm{PBHME}_{10}-b-\mathrm{PAA}_{3}-\mathrm{N}_{3}$ and cyclic- $\mathrm{PBHME}_{10}-b-\mathrm{PAA}_{3}$ upon $365 \mathrm{~nm}$ light irradiation $\left(50 \mu \mathrm{W} \mathrm{cm}{ }^{-2}\right)$ and stored in the dark for an appropriate period of time.

polymers formed spherical aggregates via self-assembly in the water/THF mixture solution (Fig. 4 and 5). The aggregate sizes of the cyclic and linear copolymers were both around $150 \pm 30 \mathrm{~nm}$, as observed from the TEM image, and about $550 \mathrm{~nm}$, as observed from the hydrodynamic diameters measured by DLS. The sizes obtained via TEM are smaller than those obtained from DLS owing to sample shrinkage during the sample preparation process for TEM measurements. Subsequently, the photo-responsive behaviors of the self-assembled aggregates were investigated by the trans-to-cis photoisomerization of azobenzene under UV light irradiation $\left(365 \mathrm{~nm}, 1 \mathrm{~mW} \mathrm{~cm}^{-2}\right.$ ) and then thermally-driven cis-to-trans return by placing the
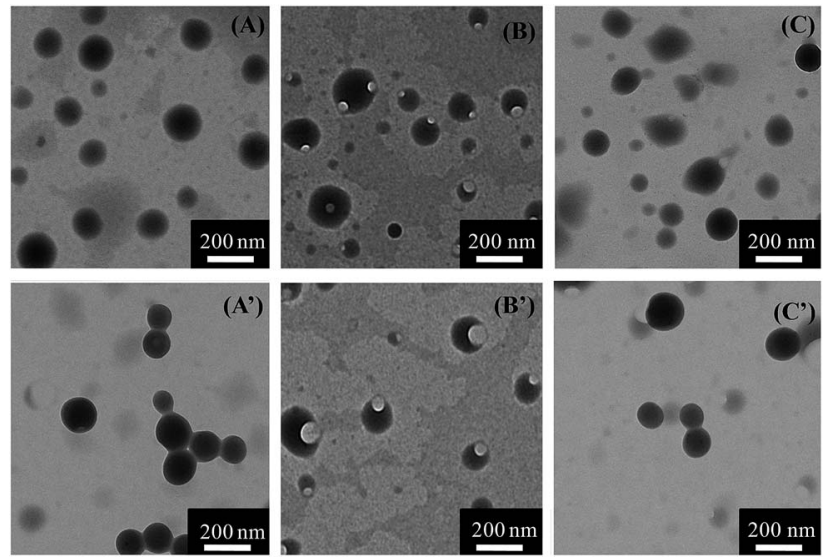

Fig. 5 TEM images of the spherical aggregates of linear and cyclic$\mathrm{PBHME}_{10}-b-\mathrm{PAA}_{3}$ formed in $\mathrm{H}_{2} \mathrm{O} / \mathrm{THF}$ solvent (initial concentration: $0.20 \mathrm{mg} \mathrm{mL}^{-1}$ in THF solvent; $\left.\mathrm{H}_{2} \mathrm{O} / \mathrm{THF}(\mathrm{v} / \mathrm{v})=3 / 10\right)$. (A) Initial aggregates formed by linear- $\mathrm{PBHME}_{10}-b-\mathrm{PAA}_{3}$; $\left(\mathrm{A}^{\prime}\right)$ initial aggregates formed by cyclic- $\mathrm{PBHME}_{10}-b-\mathrm{PAA}_{3}$; $(\mathrm{B})$ aggregates formed by linear$\mathrm{PBHME}_{10}-b-\mathrm{PAA}_{3}$ after UV irradiation for $4.2 \mathrm{~min}$; $\left(\mathrm{B}^{\prime}\right)$ aggregates formed by cyclic- $\mathrm{PBHME}_{10}-b-\mathrm{PAA}_{3}$ after $\mathrm{UV}$ irradiation for $5.5 \mathrm{~min}$; (C) aggregates of the irradiated linear- $\mathrm{PBHME}_{10}-b-\mathrm{PAA}_{3}$ after storage in the dark for $6 \mathrm{~h}$ and $\left(\mathrm{C}^{\prime}\right)$ aggregates of the irradiated cyclic-PBHME $\mathrm{E}_{10^{-}}$ $b-\mathrm{PAA}_{3}$ after storage in the dark for $10 \mathrm{~h}$. irradiated sample in the dark at room temperature until the photo-stationary states were reached. Moreover, the UV-vis absorption spectra of the aggregate solutions under the abovementioned condition of photoisomerization were obtained. As shown in Fig. 6, the absorbance at around $450 \mathrm{~nm}$ corresponding to the cis isomers increased gradually together with a decrease in the absorbance at around $358 \mathrm{~nm}$, which corresponded to the trans isomers upon UV light irradiation. Then, cis-to-trans isomerization reversal occurred when the irradiated sample was placed in the dark. It was noted that a portion of the spherical aggregates of both the linear- and cyclic-polymers became smaller after exposing the aggregate solutions to $365 \mathrm{~nm}$ light, and then, most of the aggregates re-formed after thermally-driven back-isomerization in the dark for a period of time (Fig. 5). The photo-responsive behavior of the aggregates was further confirmed by DLS measurement, which showed that the aggregate sizes reduced to around $450 \mathrm{~nm}$ for the linear structure and $220 \mathrm{~nm}$ for the cyclic structure from the initial size of $550 \mathrm{~nm}$ upon UV light irradiation, and then, both sizes recovered and became slightly larger (about $660 \mathrm{~nm}$ ) after thermal cis-to-trans relaxation. In addition, gaps appeared outside of the spherical aggregates after UV light irradiation, and especially distinct larger gaps similar to holes were observed for the cyclic-sample as compared to those for the linear sample. The reversible changing of disruption and reformation of micellar aggregates can be attributed to the unique trans-to-cis photoisomerization of azobenzene. The curved cis-configuration of azobenzene has a larger dipole moment and a shorter length between the 4 and $4^{\prime}$ positions of two benzene rings as compared to the clavated trans-configuration. The variation in the configuration and polarity between the trans and cis isomers of azobenzene mesogens can transform the hydrophilic/hydrophobic balance of amphiphilic copolymers in selective solvents during the trans-to-cis isomerization process. Upon UV light irradiation, the hydrophobic PBHME block in the micellar aggregates formed a more

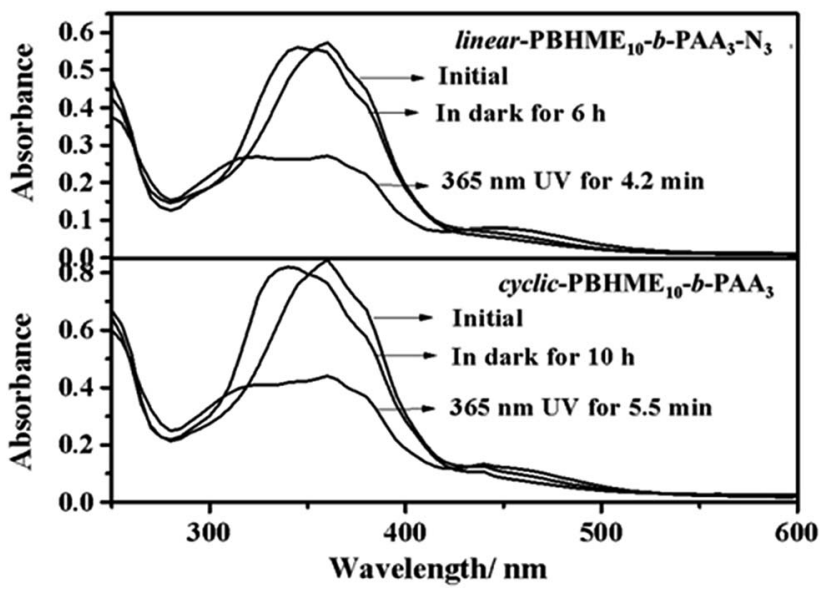

Fig. 6 UV-vis absorption changes for linear-PBHME $10-b-\mathrm{PAA}_{3}-\mathrm{N}_{3}$ and cyclic-PBHME $10-b-\mathrm{PAA}_{3}$ in THF/water solution under $365 \mathrm{~nm}$ UV light irradiation $\left(50 \mu \mathrm{W} \mathrm{cm}{ }^{-2}\right)$ and after the irradiated sample was placed in the dark at room temperature. The concentration of the solutions was $2.0 \times 10^{-5} \mathrm{~g} \mathrm{~mL}^{-1}$. 
compact region because of its configuration change via trans-tocis photoisomerization. ${ }^{26}$ As a result, the THF solvent, which was wrapped in the aggregates, diffused into the solution, resulting in gaps. The cyclic structure exhibits more sensitive photo-responsive properties such as larger changes in the size and morphology of the aggregate micelles as compared to the linear structure upon $365 \mathrm{~nm}$ light irradiation. We speculate that the cyclic amphiphile may self-assemble into relatively loose aggregates due to the rigidity of its main chain, which is imposed by the cyclic conformation, as compared to the linear amphiphile. ${ }^{51,53}$

\section{Conclusions}

In summary, well-defined cyclic block copolymers bearing hydrophobic azobenzene and hydrophilic carboxyl moieties in their side-chains, cyclic-PBHME ${ }_{m}-b-\mathrm{PAA}_{n}$, were successfully prepared via sequential ATRP and intramolecular CuAAC cyclization reaction followed by the selective hydrolysis of tertbutyl ester. The investigations on the amphiphilic block macrocycles indicate that the cyclic amphiphilic biblock copolymers display faster photoisomerization of trans-to-cis and cis-to-trans in THF than their linear precursors. In addition, the selfassembled micellar aggregates of the cyclic architecture in the mixture solution of water/THF exhibit larger changes in size and morphology upon $365 \mathrm{~nm}$ light irradiation as compared to those of their linear counterparts. These interesting differences between the cyclic- and linear copolymers could be attributed to the topological cyclic architecture, which indicated that the cyclic architecture greatly affected the photoisomerization of azobenzene and polymeric packing behaviors in micellar aggregates. This study provides new insight into the structureproperty relationship and gives guidance to future designs for the development of responsive-related functional materials. Further studies aimed at functional polymers based on azobenzene are being conducted by our research group.

\section{Acknowledgements}

This work was supported by the National Science Foundation of China (No. 21234005), the State and Local Joint Engineering Laboratory for Novel Functional Polymeric Materials, the Priority Academic Program Development of Jiangsu Higher Education Institutions (PAPD), and the Program of Innovative Research Team of Soochow University.

\section{Notes and references}

1 Y. Mai and A. Eisenberg, Chem. Soc. Rev., 2012, 41, 59695985.

2 K. Yu and A. Eisenberg, Macromolecules, 1998, 31, 35093518.

3 D. Chen and M. Jiang, Acc. Chem. Res., 2005, 38, 494-502.

4 Z. Ge and S. Liu, Chem. Soc. Rev., 2013, 42, 7289-7325.

5 C. Allen, Y. Yu, D. Maysinger and A. Eisenberg, Bioconjugate Chem., 1998, 9, 564-572.
6 Z. Zhang, R. Ma and L. Shi, Acc. Chem. Res., 2014, 47, 14261437.

7 C. Allen, D. Maysinger and A. Eisenberg, Colloids Surf., B, 1999, 16, 3-27.

8 D. Han, X. Tong and Y. Zhao, Macromolecules, 2011, 44, 437439.

9 E. Fleige, M. Quadir and R. Haag, Adv. Drug Delivery Rev., 2012, 64, 866-884.

$10 \mathrm{~J} . \mathrm{Hu}$ and S. Liu, Macromolecules, 2010, 43, 8315-8330.

11 J. Jiang, X. Tong and Y. Zhao, J. Am. Chem. Soc., 2005, 127, 8290-8291.

12 S. Uchiyama and Y. Makino, Chem. Commun., 2009, 19, 2646-2648.

13 Y. Zhao and T. Ikeda, Smart Light responsive Materials Azobenzene-Containing Polymers and Liquid Crystals, John Wiley \& Sons, Inc., Hoboken, New Jersey, 2009.

14 A. Beharry and G. Woolley, Chem. Rev., 1989, 89, 1915-1925. 15 O. Sadovski, A. Beharry, F. Zhang and G. A. Woolley, Angew. Chem., Int. Ed., 2009, 48, 1484-1486.

16 A. Beharry and G. Woolley, Chem. Soc. Rev., 2011, 40, 44224437.

17 H. Rau, Angew. Chem., Int. Ed., 1973, 12, 224-235.

18 J. Lu, F. Zhou, L. Li, Z. Zhang, F. Meng, N. Zhou and X. Zhu, RSC Adv., 2016, 6, 58755-58763.

19 S. Luo, Y. Liu, F. Wang, Q. Fei, B. Shi, J. An, C. Zhao and C. H. Tung, Analyst, 2016, 141, 2879-2882.

20 J. Rao, C. Hottinger and A. Khan, J. Am. Chem. Soc., 2014, 136, 5872-5875.

21 A. Wong, A. Prinzen and E. Gillies, Polym. Chem., 2016, 7, 1871-1881.

22 Y. Zhao, Macromolecules, 2012, 45, 3647-3657.

23 R. Dong, B. Zhu, Y. Zhou, D. Yan and X. Zhu, Polym. Chem., 2013, 4, 912-915.

24 K. Han, W. Su, M. Zhong, Q. Yan, Y. Luo, Q. Zhang and Y. Li, Macromol. Rapid Commun., 2008, 29, 1866-1870.

25 X. Tong, G. Wang, A. Soldera and Y. Zhao, J. Phys. Chem. B, 2005, 109, 20281-20287.

26 D. Wang and X. Wang, Prog. Polym. Sci., 2013, 38, 271-301.

27 E. Blasco, B. V. K. J. Schmidt, C. Barner-Kowollik, M. Pinol and L. Oriol, Macromolecules, 2014, 47, 3693-3700.

28 W. Sun, X. He, C. Gao, X. Liao, M. Xie, S. Lin and D. Yan, Polym. Chem., 2013, 4, 1939-1949.

29 J. A. Lv, Y. Liu, J. Wei, E. Chen, L. Qin and Y. Yu, Nature, 2016, 537, 179-184.

30 R. Walker, H. Audorff, L. Kador and H. Schmidt, Adv. Funct. Mater., 2009, 19, 2630-2638.

31 J. Lu, A. Xia, N. Zhou, W. Zhang, Z. Zhang, X. Pan, Y. Yang, Y. Wang and X. Zhu, Chem.-Eur. J., 2015, 21, 2324-2329.

32 S. Iamsaard, S. J. Asshoff, B. Matt, T. Kudernac, J. Cornelissen, S. P. Fletcher and N. Katsonis, Nat. Chem., 2014, 6, 229-235.

33 J. Lu, G. Jiang, Z. Zhang, W. Zhang, Y. Yang, Y. Wang, N. Zhou and X. Zhu, Polym. Chem., 2015, 6, 8144-8149.

34 P. Weis, D. Wang and S. Wu, Macromolecules, 2016, 49, 63686373.

35 Y. Zhao and J. He, Soft Matter, 2009, 5, 2686-2693. 
36 K. Zhang, M. A. Lackey, J. Cui and G. N. Tew, J. Am. Chem. Soc., 2011, 133, 4140-4148.

37 S. Honda, T. Yamamoto and Y. Tezuka, Nat. Commun., 2013, 4, 1-9.

38 S. H. Lahasky, X. Hu and D. Zhang, ACS Macro Lett., 2012, 1, 580-584.

39 J. Poelma, K. Ono, D. Miyajima, T. Aida, K. Satoh and C. J. Hawker, ACS Nano, 2012, 6, 10845-10854.

40 X. Zhu, N. Zhou, Z. Zhang, B. Sun, Y. Yang, J. Zhu and X. Zhu, Angew. Chem., Int. Ed., 2011, 50, 6615-6618.

41 X. Wan, T. Liu and S. Liu, Biomacromolecules, 2011, 12, 11461154.

42 M. D. Hossain, D. Lu, Z. Jia and M. J. Monteiro, ACS Macro Lett., 2014, 3, 1254-1257.

43 M. A. Cortez, W. T. Godbey, Y. Fang, M. E. Payne, B. J. Cafferty, K. A. Kosakowska and S. M. Grayson, J. Am. Chem. Soc., 2015, 137, 6541-6549.

44 C. W. Bielawski, D. Benitez and R. H. Grubbs, Science, 2002, 297, 2041-2044.

45 H. Zhang, W. Wu, X. Zhao and Y. Zhao, Macromolecules, 2017, 50, 3411-3423.

46 D. Han, X. Tong, Y. Zhao, T. Galstian and Y. Zhao, Macromolecules, 2010, 43, 3664-3671.

47 H. Zhang, N. Zhou, X. Zhu, X. Chen, Z. Zhang, W. Zhang, J. Zhu, Z. Hu and X. Zhu, Macromol. Rapid Commun., 2012, 33, 1845-1851.

48 Y. Sun, Z. Wang, Y. Li, Z. Zhang, W. Zhang, X. Pan, N. Zhou and X. Zhu, Macromol. Rapid Commun., 2015, 36, 1341-1347.
49 K. Heo, Y. Y. Kim, Y. Kitazawa, M. Kim, K. S. Jin, T. Yamamoto and M. Ree, ACS Macro Lett., 2014, 3, 233-239.

50 R. J. Williams, A. Pitto-Barry, N. Kirby, A. P. Dove and R. K. O'Reilly, Macromolecules, 2016, 49, 2802-2813.

51 X. Fan, B. Huang, G. Wang and J. Huang, Macromolecules, 2012, 45, 3779-3786.

52 S. Honda, T. Yamamoto and Y. Tezuka, J. Am. Chem. Soc., 2010, 132, 10251-10253.

53 D. E. Lonsdale and M. J. Monteiro, J. Polym. Sci., Part A: Polym. Chem., 2011, 49, 4603-4612.

54 Y. Dong, Y. Tong, B. Dong, F. Du and Z. Li, Macromolecules, 2009, 42, 2940-2948.

55 M. Schappacher and A. Deffieux, Science, 2008, 319, 15121515.

56 Y. Li, H. Su, X. Feng, K. Yue, Z. Wang, Z. Lin, X. Zhu, Q. Fu, Z. Zhang, S. Z. D. Cheng and W. Zhang, Polym. Chem., 2015, 6, 827-837.

57 B. Laurent and S. Grayson, J. Am. Chem. Soc., 2006, 128, 4238-4239.

58 G. Huang, J. Zhu, Z. Zhang, W. Zhang, N. Zhou and X. Zhu, J. Macromol. Sci., Part A: Pure Appl. Chem., 2013, 50, 193-199.

59 Y. Cai, J. Lu, F. Zhou, X. Zhou, N. Zhou, Z. Zhang and X. Zhu, Macromol. Rapid Commun., 2014, 35, 901-907.

60 H. Durmaz, A. Dag, G. Hizal and U. Tunca, J. Polym. Sci., Part A: Polym. Chem., 2011, 49, 1195-1200.

61 H. Durmaz, A. Dag, G. Hizal and U. Tunca, J. Polym. Sci., Part A: Polym. Chem., 2010, 48, 5083-5091.

62 G. Nossarev and T. Hogen-Esch, Macromolecules, 2002, 35, 1604-1610. 